УДК 622.276

\title{
РАЗРАБОТКА ДИЗАЙНА ГИДРОДИНАМИЧЕСКОГО ИССЛЕДОВАНИЯ В УСЛОВИЯХ КАРБОНАТНОГО КОЛЛЕКТОРА
}

\author{
Давыдова Анастасия Евгеньевна ${ }^{1,2}$, \\ DavydovaAE@knipi.rosneft.ru
}

Щуренко Александр Александрович ${ }^{1,2}$, ShchurenkoAA@knipi.rosneft.ru

Дадакин Никита Михайлович ${ }^{12}$, DadakinNM@knipi.rosneft.ru

\section{Шуталев Артем Дмитриевич ${ }^{12,}$, ShutalevAD@knipi.rosneft.ru}

\author{
Квеско Бронислав Брониславович', \\ kveskobb@gmail.com \\ 1 Институт нефти и газа Сибирского Федерального университета, \\ Россия, 660041, г. Красноярск, пр. Свободный, 79. \\ 2000 «РН-КрасноярскНИПИнефть», \\ Россия, 660022, г. Красноярск, ул. Партизана Железняка, 24в.
}

Актуальность исследования обусловлена необходимостью совершенствования методов гидродинамических исследований скважин вследствие неоднозначности интерпретации результатов в условиях карбонатного коллектора. Приоритетами при проведении гидродинамических исследований скважин являются максимальное качество получаемой информации о фильтрационно-емкостных свойствах пластов и минимальные потери добычи нефти в ходе остановки скважин на исследования. С целью выполнения данных задач актуальной является разработка дизайна гидродинамических исследований скважин, предлагаемая в статье. Дизайн позволит обеспечить комплексный подход к моделированию процесса проведения исследований и прогноза получаемых данных

Цель: разработать дизайн гидродинамических исследований скважин с целью оптимизации времени проведения исследований и сокращения периода остановки скважин на этапе опытно-промышленной эксплуатации; подтвердить экономическую эффективность представленной методики

Объекты: скважины Т-23, T-361, Т-388 месторождения А, продуктивные отложения которого преимущественно представлены кавернозно-трещиноватыми карбонатными породами рифейского возраста.

Методы. Поставленные задачи исследования решались теоретически и экспериментально в промысловых условиях. При этом был выполнен анализ публикаций по данной проблеме; проведены промысловые гидродинамические исследования скважин, вскрывающих низкопроницаемый карбонатный коллектор; выполнено моделирование гидродинамических исследований, выполнены сравнительные расчёты по обработке результатов с помощью программного комплекса Saphir компании «KAPPA Engineering».

Результаты. Приведены результаты разработки дизайна гидродинамических исследований в условиях карбонатного коллектора. Проанализированы данные гидродинамических исследований для 12 скважин, эксплуатирующих рифейские карбонатные отложения, за период с 2005-2008 гг. представлены результаты по трем скважинам: T-23, T-361, T-388. Представлена методика моделирования гидродинамических исследований в программном комплексе Saphir компании "KAPPA Engineering». Приведен пример расчета времени стабилизации при исследовании скважины методом установившихся отборов, а также оценка оптимального времени регистрации кривой восстановления давления. Также приведено сравнение стандартной методики, которой руководствуются при испытании скважины - РД (руководящий документ) 153-39.0-109-01 «Методические указания по комплексированию и этапность выполнения геофизических, гидродинамических и геохимических исследований нефтяных и нефтегазовых месторождений», с методикой, представленной в статье. На основе данного сравнения была установлена экономическая эффективность.

\section{Ключевые слова:}

Гидродинамические исследования скважин, кривая восстановления давления, дизайн, длительность исследования скважины, карбонатный коллектор, нефтегазовое месторождение.

\section{Введение}

В мировом балансе энергоносителей доля углеводородов, сосредоточенных в карбонатных коллекторах, играет все более существенную роль. Запасы нефти, приуроченные к карбонатным коллекторам с содержанием в них вязкой и высоковяз- кой нефти, к настоящему времени составляют в мире более $30 \%$ от всех разведанных запасов [1, 2]. В России запасы нефти в таких коллекторах составляют более 50 \% от всех. Наиболее крупными активами с такими залежами являются: Восточный участок Оренбургского месторождения, Куюмбин- 
ское и Западно-Чонское месторождения в Восточной Сибири, проект Бадра в Ираке, Приразломное месторождение на шельфе Печорского моря [3].

В статье рассматривается месторождение A, продуктивные отложения которого преимущественно представлены крепкими трещиноватыми карбонатными породами рифейского возраста. Рифейские отложения сложены в нижней части терригенными отложениями (зелендуконская и вэдрэшевская толщи), перекрытыми глинисто-карбонатными отложениями мадринской толщи. Выше залегает около 2500 м отложений преимущественно карбонатного состава, состоящих из чередования карбонатных пачек, толщиной около 500 м каждая, и глинистокарбонатных пачек, толщина каждой из которых составляет порядка 100-200 м. Карбонатные пачки на 90-95\% представлены доломитами и на 10-5 \% - прослоями аргиллитов. В глинисто-карбонатных пачках прослои аргиллитов занимают от 30 до $70 \%$ общей толщины. Мощность прослоев аргиллитов изменяется от первых миллиметров до нескольких метров [4].

В процессе формирования карбонатных породколлекторов решающее значение имеют как условия образования осадков, так и вторичные постседиментационные преобразования карбонатных пород. По совокупности геохимических признаков условий осадконакопления формирование свиты месторождения А предположительно происходило в морских опресненных условиях со значительными локальными влияниями пресноводных масс. Формирование ёмкостного пространства в карбонатных породах происходило на всех стадиях литогенеза. Первичная седиментационная структура карбонатных осадков предопределяет дальнейшее развитие постседиментационных процессов, что в совокупности окончательно формирует ёмкостные и фильтрационные свойства карбонатных пород. Первичная пористость в органогенных постройках значительно выше, чем в тонкозернистых иловых осадках и обусловлена наличием пустотного пространства в строматолитовых и водорослевых доломитах. Плотная упаковка первичных седиментационных илов и отсутствие органических остатков предопределяют их низкую пористость. Матрица практически непроницаема и ее пористость находится в пределах 0,1-1 \% [5].

Следует отметить значительное влияние трещиноватости на условия фильтрации флюидов в карбонатных породах венда и рифея. Этим обусловлено преимущественное развитие в них коллекторов сложного типа: трещинно-поровых, поровотрещинных, трещеновато-кавернозных. Трещиноватость является одним из факторов, способствующих не только фильтрации углеводородов, но и образованию вторичной емкости. Многочисленными исследованиями, проведенными во Всероссийском нефтяном научно-исследовательском геологоразведочном институте (ВНИГРИ), установлено, что густота трещин с глубиной не возрастает, но увеличивается ее роль в формировании фильтрационно- ёмкостных свойств. С глубиной возрастает и значение трещин как основных путей фильтрации. Как показывают результаты исследований, ёмкость трещин крайне низкая и в сильнотрещиноватых породах не превышает 0,03-0,05 \% [6]. Поэтому трещины ёмкостью не являются, а служат в основном путями фильтрации углеводородов и косвенно принимают участие в образовании вторичных пор выщелачивания. Вторичные поры выщелачивания, развитые вдоль открытых трещин, составляют 0,5-2,5\%, в сильно трещиноватых породах достигают 5-6 \% [7].

В табл. 1 представлены основные геологические характеристики месторождения $\mathrm{A}$.

таблица 1. Геологические характеристики месторождения А

Table 1. Oilfield A geological characteristics

\begin{tabular}{|c|c|c|}
\hline $\begin{array}{l}\text { Параметр } \\
\text { Parameter }\end{array}$ & \multicolumn{2}{|c|}{$\begin{array}{c}\text { Характеристика } \\
\text { Characteristic }\end{array}$} \\
\hline $\begin{array}{l}\text { Фазовое состояние } \\
\text { Phase state }\end{array}$ & \multicolumn{2}{|c|}{$\begin{array}{l}\text { Нефтегазоконденсатная } \\
\text { Oil-gas-condensate }\end{array}$} \\
\hline $\begin{array}{c}\text { Тип залежи } \\
\text { Accumulation type }\end{array}$ & \multicolumn{2}{|c|}{$\begin{array}{l}\text { Массивная, тектонически-экранированная } \\
\text { Massive, fault-bounded }\end{array}$} \\
\hline \multirow{2}{*}{$\begin{array}{l}\text { Тип коллектора } \\
\text { Reservoir type }\end{array}$} & $\begin{array}{l}\text { Литологический состав } \\
\text { Lithological composition }\end{array}$ & $\begin{array}{l}\text { Карбонатный } \\
\text { Carbonaceous }\end{array}$ \\
\hline & $\begin{array}{c}\text { По типу пустотного } \\
\text { пространства } \\
\text { Voids }\end{array}$ & $\begin{array}{c}\text { Кавернозно- } \\
\text { трещинный } \\
\text { Cavernous-fissured }\end{array}$ \\
\hline
\end{tabular}

Месторождение А относится к месторождениям очень сложного геологического строения со следующими характеристиками:

- высокая степень литолого-фациальной неоднородности;

- значительная дезинтегрированность;

- изотропия фильтрационных свойств;

- интенсивный обменный поток жидкости между трещинами и матрицей.

Данные параметры являются причиной недостижения радиального режима фильтрации. С одной стороны, радиальное течение может «маскироваться» влиянием эффекта ствола скважины либо линейным течением в случае скважины с трещиной. С другой стороны, радиальный режим притока может быть искажен проявлением граничных условий, таких как:

- интерференция с окружающими скважинами;

- наличие непроницаемой границы (геологический разлом, фациальное замещение);

- процессы, происходящие в стволе скважины;

- наличие газовой шапки (или другой границы постоянного давления).

Вследствие сложного характера потоков интерпретация результатов ГДИ в условиях карбонатного коллектора является не простой задачей. С целью устранения неоднозначности получаемой информации в данной статье предлагается разработка комплексного подхода к моделированию процесса проведения исследований и прогноза получаемых данных с помощью дизайна.

Данный метод позволяет:

- прогнозировать длительность работы на режиме; 
- прогнозировать длительность остановки на КВД, при этом общая продолжительность ГДИ определяется с учетом наименьших потерь времени эксплуатации скважин и добычи углеводородов;

- учитывать технические и технологические условия проведения работ;

- определить наиболее часто проявляющиеся факторы и принять меры по уменьшению их негативного влияния на проведение ГДИ;

- оценить возможности получения фильтрационно-ёмкостных свойств (ФЕС) пласта и параметров скважины по КВД;

- оценить потери по добыче нефти.

В статье приводятся результаты анализа данных исследований трех добывающих скважин, которые вскрыли продуктивный горизонт, представленный карбонатными отложениями рифейского возраста. В 2018 г. на месторождении А, в рамках проекта пробной эксплуатации, планируется переиспытание скважин Т-23, Т-361, Т-388 с проведением ГДИ методом установившихся отборов и методом неустановившейся фильтрации (регистрация забойного давления после остановки скважины). После проведения ГДИ планируется запуск скважины в пробную эксплуатацию.

Дизайн гидродинамических исследований был разработан в программном продукте Saphir пакета Ecrin компании KAPPA Engineering [8]. В качестве исходной информации используются следующие данные:

\section{Характеристика скважин-кандидатов}

Первые гидродинамические исследования скважин Т-23, Т-361, Т-388 проводились в 2007 г. Вторичное вскрытие выполнено кумулятивной перфорацией ПКО-89С, плотность прострела для скважины Т-23 составила 14 отверстий/погонный метр, для скважин Т-361 и Т-388 20 отверстий/погонный метр. Для вызова притока было проведено несколько циклов свабирования, с созданием депрессии до 35 \% от пластового давления, после чего скважина перешла в режим фонтанирования.

Для формирования дизайна исследования была использована реальная работа скважин. В табл. 2 представлены основные параметры скважин-кандидатов.

Таблица 2. Характеристика скважин

Table 2. Well characteristics

\begin{tabular}{|c|c|c|c|}
\hline Параметр/Parameter & \multicolumn{3}{|c|}{ Характеристика/Characteristic } \\
\hline Скважина/Well & Т-23 & Т-36 & T-388 \\
\hline Назначение/Purpose & \multicolumn{3}{|c|}{ Разведочная/Exploratory } \\
\hline Тип/Type & \multicolumn{3}{|c|}{ Вертикальная/Vertical } \\
\hline Дебит, $\mathrm{m}^{3} /$ сут $/$ Flow rate, $\mathrm{m}^{3} / \mathrm{d}$ & 182,8 & 309,0 & 136,0 \\
\hline
\end{tabular}

\section{PVT- свойства флюида, параметры пласта}

В табл. 3, 4 представлены свойства флюидов и параметры пласта. таблица 3. Свойства флюидов

Table 3. Fluids properties

\begin{tabular}{|c|c|c|c|c|}
\hline $\begin{array}{l}\text { Параметр } \\
\text { Parameter }\end{array}$ & $\begin{array}{l}\text { Ед. изм. } \\
\text { Unit of mea- } \\
\text { sure }\end{array}$ & T-23 & $\mathrm{T}-361$ & T-388 \\
\hline $\begin{array}{l}\text { Начальное пластовое давление } \\
\text { Initial reservoir pressure }\end{array}$ & $\begin{array}{l}\mathrm{k} \Gamma \mathrm{c} / \mathrm{cm}^{2} \\
\mathrm{kp} / \mathrm{cm}^{2}\end{array}$ & 216 & 200.6 & 200.6 \\
\hline $\begin{array}{l}\text { Вязкость пластовой нефти } \mu_{0} \\
\text { Formation oil viscosity }\end{array}$ & $\begin{array}{l}\mathrm{c} \Pi 3 \\
\mathrm{cPs}\end{array}$ & 1,332 & 1,06 & 1,06 \\
\hline $\begin{array}{l}\text { Объемный коэффициент нефти } \mathrm{B}_{0} \\
\text { Formation volume factor }\end{array}$ & $\begin{array}{c}\text { д.ед. } \\
\text { unit fraction }\end{array}$ & 1,288 & 1,465 & 1,465 \\
\hline $\begin{array}{l}\text { Плотность нефти (пласт. усл.) } \rho_{\text {оп.у }} \\
\text { Oil density (reservoir conditions) }\end{array}$ & $\begin{array}{l}\Gamma / \mathrm{CM}^{3} \\
\mathrm{~g} / \mathrm{cc}\end{array}$ & 0,714 & 0,7 & 0,7 \\
\hline $\begin{array}{l}\text { Плотность нефти (станд. усл.) } \rho_{\text {ос.у }} \\
\text { Oil density (standard conditions) }\end{array}$ & $\begin{array}{l}\Gamma / \mathrm{cM}^{3} \\
\mathrm{~g} / \mathrm{cc}\end{array}$ & 0,822 & 0,825 & 0,825 \\
\hline $\begin{array}{l}\text { Полная сжимаемость Ct } \\
\text { Total compressibility }\end{array}$ & $\begin{array}{l}1 / \mathrm{M \Pi a} \cdot 10^{-4} \\
1 / \mathrm{MPa} \cdot 10^{-4}\end{array}$ & 18,3 & 18,3 & 18,3 \\
\hline
\end{tabular}

Таблица 4. Параметры пласта

Table 4. Reservoir characteristics

\begin{tabular}{|c|c|c|}
\hline Параметр/Parameter & $\begin{array}{c}\text { Ед. изм. } \\
\text { Unit of measure }\end{array}$ & $\begin{array}{c}\text { Значение } \\
\text { Value }\end{array}$ \\
\hline $\begin{array}{c}\text { Эффективная толщина пласта, } \mathrm{H}_{\text {эфф }} \\
\text { Net thickness }\end{array}$ & $\mathrm{m} / \mathrm{m}$ & 93,2 \\
\hline $\begin{array}{c}\text { Средняя пористость коллектора, } \varphi \\
\text { Меan reservoir porosity }\end{array}$ & $\begin{array}{c}\text { д.ед. } \\
\text { unit fraction }\end{array}$ & 0,01 \\
\hline
\end{tabular}

\section{Подбор оборудования}

Для проведения ГДИ предполагается использование прибора «САМТ-02». Данный глубинный манометр-термометр предназначен для регистрации значений давления и температуры по стволу скважины и изменения их во времени в любой точке, например на забое при снятии кривой восстановления давления (КВД) [9]. Основными преимуществами приборы являются:

- скоростной режим замера для обеспечения оперативности исследования;

- регулирование режима работы и передача данных без разборки корпуса.

Таблица 5. Краткие технические характеристики «САМТ-02» Table 5. «SAMT-02» technical characteristics summary

\begin{tabular}{|c|c|c|}
\hline Параметр/Parameter & \begin{tabular}{|c|} 
Ед. изм. \\
Unit of measure
\end{tabular} & $\begin{array}{c}\text { Значение } \\
\text { Value }\end{array}$ \\
\hline $\begin{array}{l}\text { Диапазон измерения давления } \\
\text { Pressure measuring range }\end{array}$ & $\mathrm{M \Pi a} / \mathrm{MPa}$ & $0-60$ \\
\hline $\begin{array}{l}\text { Предельно допустимые условия } \\
\text { эксплуатации } \\
\text { Maximum permissible conditions } \\
\text { of exploitation }\end{array}$ & ${ }^{\circ} \mathrm{C}$ & $-40 \ldots+125$ \\
\hline $\begin{array}{l}\text { Минимальная дискретность измерения } \\
\text { Minimal measurement resolution }\end{array}$ & $\mathrm{c} / \mathrm{s}$ & $1 / 128$ \\
\hline $\begin{array}{l}\text { Время непрерывной работы от свежей } \\
\text { батареи } \\
\text { Running time of battery operation }\end{array}$ & Ед./Unit & $\begin{array}{l}\text { до } 1 \text { года } \\
1 \text { year }\end{array}$ \\
\hline $\begin{array}{l}\text { Разрешающая способность по давлению } \\
\text { Resolving power by pressure }\end{array}$ & $\mathrm{M \Pi a} / \mathrm{MPa}$ & 0,0001 \\
\hline $\begin{array}{l}\text { Максимальная скорость записи } \\
\text { Maximum-usable writing speed }\end{array}$ & $\mathrm{c} / \mathrm{s}$ & 1 \\
\hline $\begin{array}{l}\text { Погрешность измерений давления } \\
\text { от полной шкалы } \\
\text { Error of the pressure measurement } \\
\text { sof full scale range }\end{array}$ & $\%$ & 0,15 \\
\hline
\end{tabular}


В качестве исходных данных для формирования дизайна исследования использовались характеристики оборудования, приведенные в табл. 5 .

\section{Формирование программы исследований}

В статье рассматривается дизайн индикаторной диаграммы (ИД) с прямым и обратным ходом методом монотонно-ступенчатого изменения дебита.

В основе всех модификаций вариантов исследования с помощью ИД лежит метод установившихся отборов. Обязательными требованиями к проведению исследований методом установившихся отборов являются: полное восстановление давления в ходе остановки скважины и полная стабилизация на режиме [10]. Известно, что в случае низкопроницаемых коллекторов такой процесс требует длительного времени.

Исследование состоит из четырех режимов прямого хода (с минимального штуцера), остановки на КВД и двух режимов обратного хода. Режимы обратного хода применяются для контроля за очисткой скважины и ухудшением свойств призабойной зоны. Запись КВД после окончания прямого хода целесообразна, т. к. на последнем режиме прямого хода происходит работа с максимальным дебитом, что обуславливает максимальное значение производной давления при КВД. Таким образом, создаются наиболее благоприятные условия для очистки забоя от жидкости и механических примесей, что обеспечивает хорошее качество КВД $[11,12]$.

При проведении исследований для рассматриваемых скважин месторождения А методом установившихся отборов время стабилизации рассчитывается по формуле:

$$
t_{y}=\frac{R_{k}^{2}}{4 \chi},
$$

где $R_{k}$ - радиус контура питания, или половина расстояния до соседних скважин, м; $\chi$ - пьезопроводность пласта, $\mathrm{M}^{2} / \mathrm{c}$.

Оценка продолжительности работы скважины на каждом режиме осуществляется на основе выхода скважины на установившийся режим. Коэффициент пьезопроводности пласта рассчитывается по формуле:

$$
\chi=\frac{k}{\mu \beta^{*}},
$$

где $k$ - проницаемость пласта, $\mathrm{m}^{2} ; \mu$ - динамическая вязкость пластового флюида, Пасс; $\beta^{*}$ - упругоемкость пласта, $\Pi^{-1}$.

В качестве исходных данных для построения дизайна приняты данные ГДИ, проведенного в 2007 г. (проницаемость, влияния ствола скважины (ВСС), дебит) [13]. При моделировании использовано нейтральное значение механического скинфактора, равное 0. В табл. 6 представлены исходные данные и расчетное время, необходимое для работы скважины на каждом режиме.

На рис. 1-3 представлены модели дизайна исследований скважин Т-23, Т-361, Т-388. Согласно результатам проведенного моделирования, для получения качественной ИД необходима работа скважины на каждом режиме (без учёта времени необходимого для смены режима) не менее:

- 42 ч для скважины Т-23;

- 17 ч для скважины Т-361;

- 19 ч для скважины Т-388.

Таблица 6. Рекомендуемые режимы работы скважины

\begin{tabular}{|c|c|c|c|}
\hline $\begin{array}{l}\text { Технология } \\
\text { Technology }\end{array}$ & $\begin{array}{l}\text { Штуцер, мм } \\
\text { Flow choke, } \\
\text { mm }\end{array}$ & $\begin{array}{l}\text { Длитель- } \\
\text { ность, ч } \\
\text { Period, h }\end{array}$ & $\begin{array}{c}\text { Расчетный } \\
\text { дебит, } \mathrm{m}^{3} / \text { сут. } \\
\text { Design } \\
\text { flowrate, } \mathrm{m}^{3} / \mathrm{d}\end{array}$ \\
\hline \multicolumn{4}{|c|}{ Скважина T-23/Well T-23 } \\
\hline $\begin{array}{c}\text { Очистка ПЗП } \\
\text { Bottom-hole treatment }\end{array}$ & 10 & 24 & 149,8 \\
\hline \multicolumn{4}{|l|}{ КВД/PBU } \\
\hline \multirow{4}{*}{$\begin{array}{c}\text { Прямой ход } \\
\text { Forward stroke }\end{array}$} & 6 & 42 & 64,9 \\
\hline & 8 & 42 & 113,2 \\
\hline & 10 & 42 & 149,8 \\
\hline & 12 & 42 & 182,8 \\
\hline \multicolumn{4}{|l|}{ КВД/PВU } \\
\hline \multirow{2}{*}{$\begin{array}{l}\text { Обратный ход } \\
\text { Return stroke }\end{array}$} & 10 & 42 & 149,8 \\
\hline & 8 & 42 & 113,2 \\
\hline \multicolumn{4}{|c|}{ Скважина T-361/Well T-361 } \\
\hline \multirow{2}{*}{$\begin{array}{c}\begin{array}{c}\text { Очистка ПЗП } \\
\text { Bottom-hole treatment }\end{array} \\
\text { КВД/PBU } \\
\end{array}$} & 10 & 24 & 216 \\
\hline & & & \\
\hline \multirow{4}{*}{$\begin{array}{c}\text { Прямой ход } \\
\text { Forward stroke }\end{array}$} & 6 & 17 & 121,9 \\
\hline & 8 & 17 & 166,1 \\
\hline & 10 & 17 & 216 \\
\hline & 12 & 17 & 309 \\
\hline \multicolumn{4}{|l|}{ КВД/PBU } \\
\hline \multirow{2}{*}{$\begin{array}{l}\text { Обратный ход } \\
\text { Return stroke }\end{array}$} & 10 & 17 & 216 \\
\hline & 8 & 17 & 166,1 \\
\hline \multicolumn{4}{|c|}{ Скважина T-388 Well T-388 } \\
\hline \multirow{3}{*}{$\begin{array}{c}\begin{array}{c}\text { Очистка ПЗП } \\
\text { Bottom-hole treatment }\end{array} \\
\text { КВД/PBU } \\
\end{array}$} & 10 & 24 & 123 \\
\hline & & & \\
\hline & 6 & 19 & 70 \\
\hline \multirow{3}{*}{$\begin{array}{l}\text { Прямой ход } \\
\text { Forward stroke }\end{array}$} & 8 & 19 & 93 \\
\hline & 10 & 19 & 123 \\
\hline & 12 & 19 & 136 \\
\hline \multicolumn{4}{|l|}{ КВД/PВU } \\
\hline \multirow{2}{*}{$\begin{array}{l}\text { Обратный ход } \\
\text { Return stroke }\end{array}$} & 10 & 19 & 123 \\
\hline & 8 & 19 & 93 \\
\hline
\end{tabular}
Table 6. Well performance parameters

В результате численного моделирования были получены диагностические графики КВД. На рис. 4 представлен детализированный график для скважины Т-23.

Согласно выполненному моделированию, время окончания ВСС составило 12 часов, начало выхода на радиальный режим течения диагностируется спустя 35 часов.

С целью получения корректных результатов при интерпретации КВД на скважине Т-23 длительность радиального режима должна составить не менее $1 / 2$ логарифмического цикла. С учётом указанного условия длительность регистрации КВД составит порядка 100 часов (4 суток).

В результате выполненного дизайна был произведен тщательный анализ исходных данных и про- 


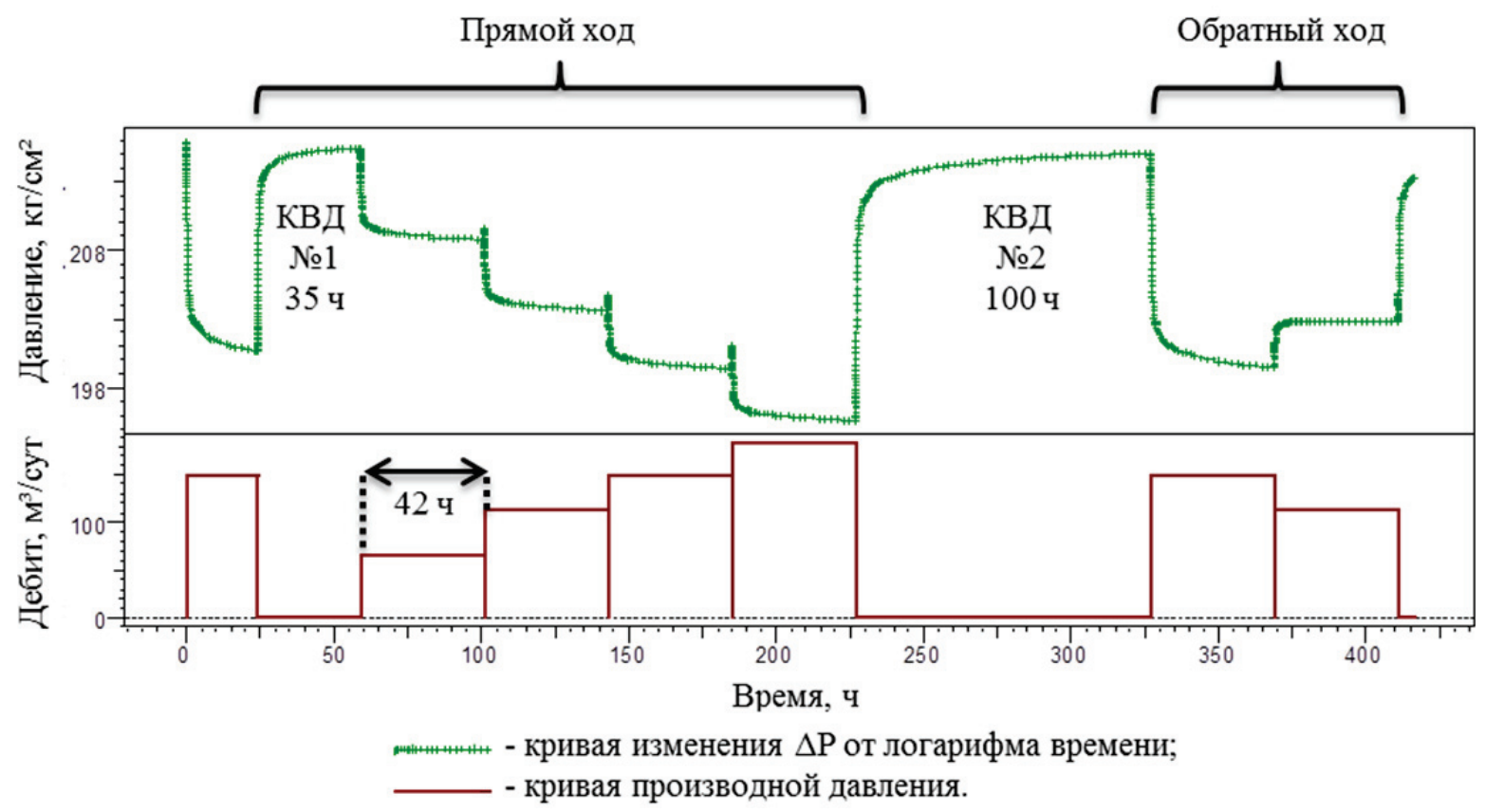

Pис. 1. Дизайн исследования скважины Т-23

Fig. 1. Research design of well T-23

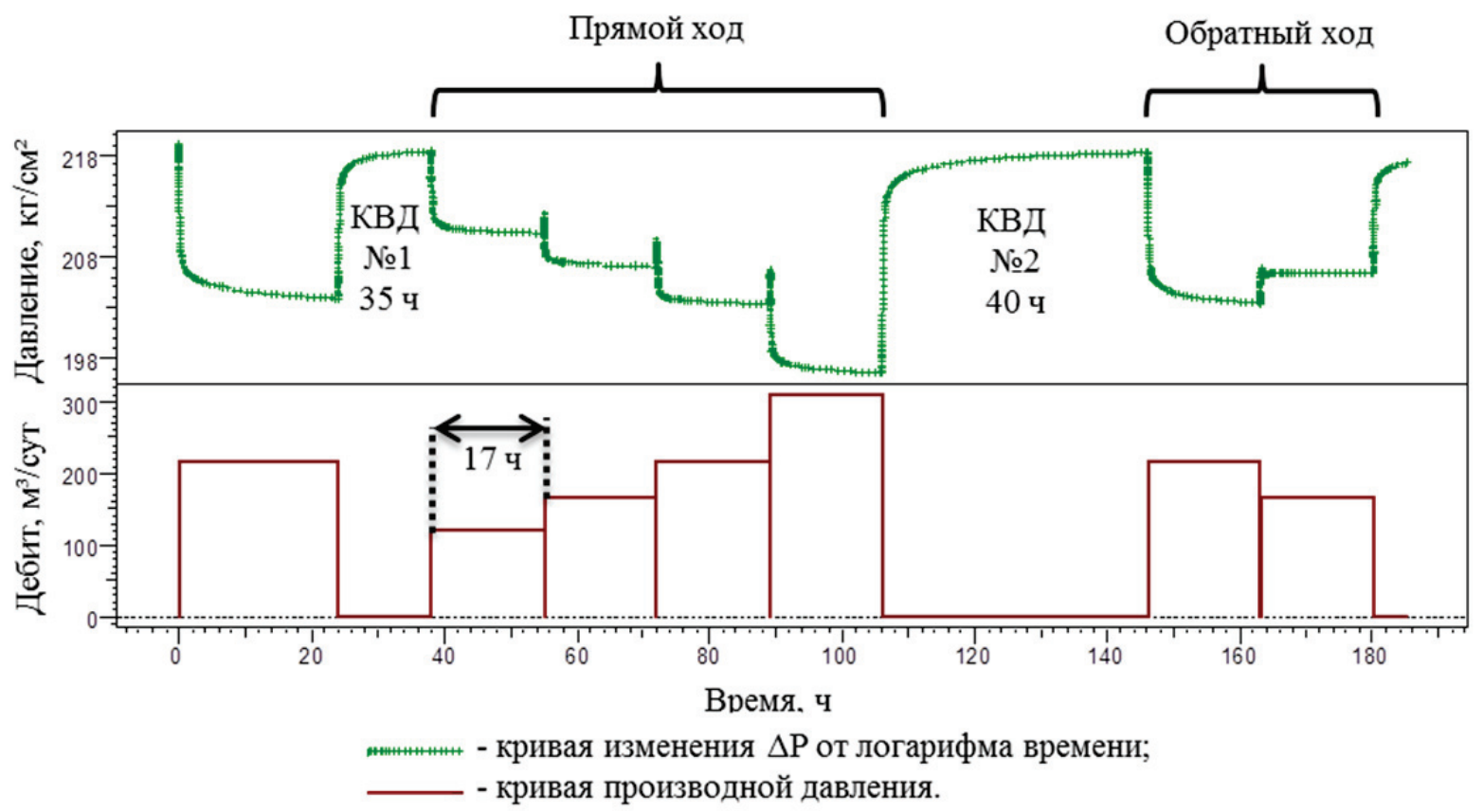

Pис. 2. Дизайн исследования скважины T-361

Fig. 2. Research design of well T-361

изведено численное моделирование поведения забойного давления для скважин Т-23, Т-361, Т-388. По результатам моделирования исследования рекомендованная продолжительность исследования составляет:

- Т-23- 100 ч;

- T-361- 40 ч;

- $\mathrm{T}-388-35$ ч.
Также в рамках данной работы удалось провести сопоставление дизайна исследования с реальными результатами испытания для скважины T-23.

Необходимо отметить, что регистрация кривой восстановления давления проводилась в течении 144 часов - в соответствии с рекомендациями, указанными в РД 153-39.0-109-01. 


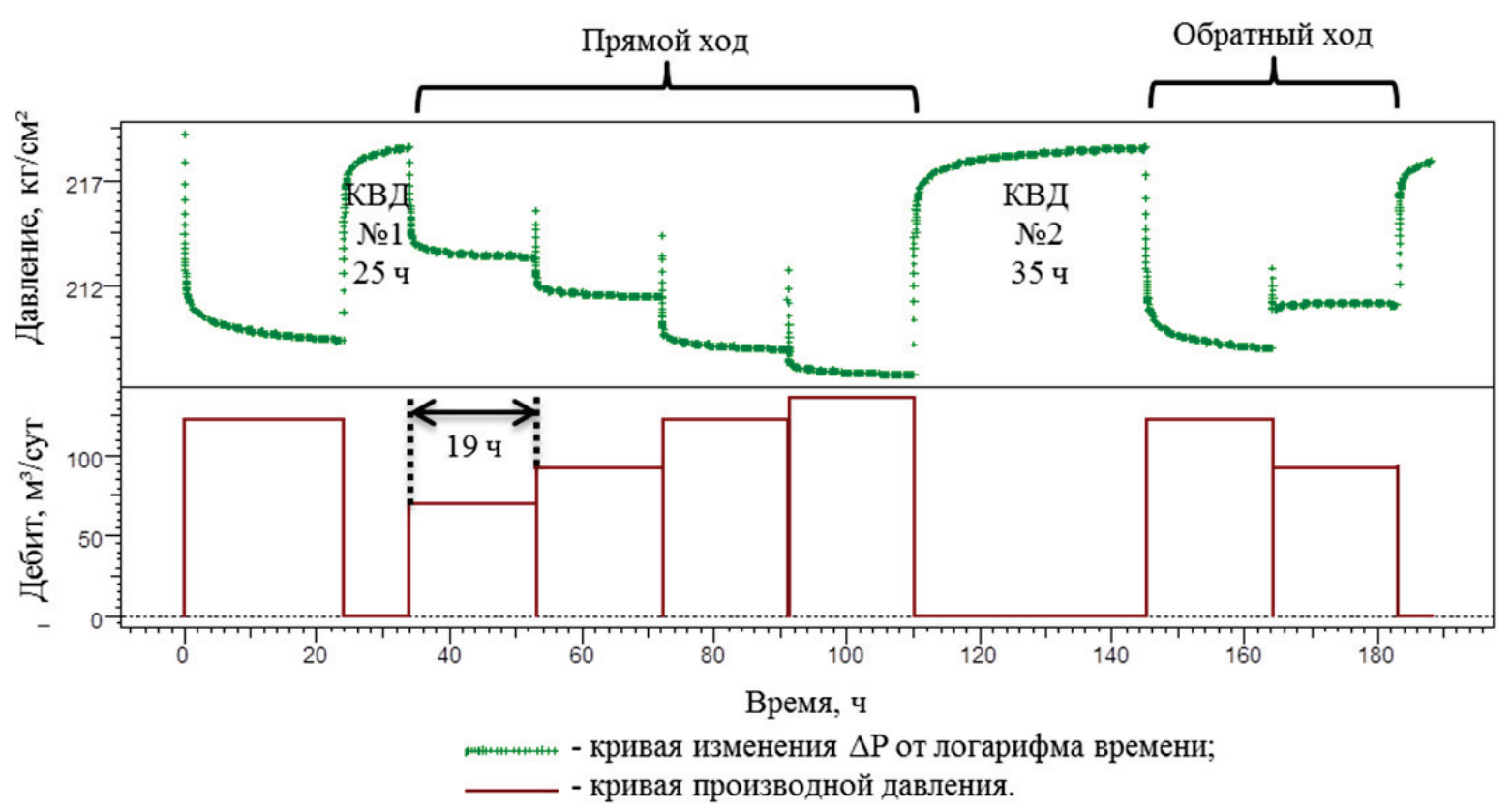

Pис. 3. Дизайн исследования скважины Т-388

Fig. 3. Research design of well T-388

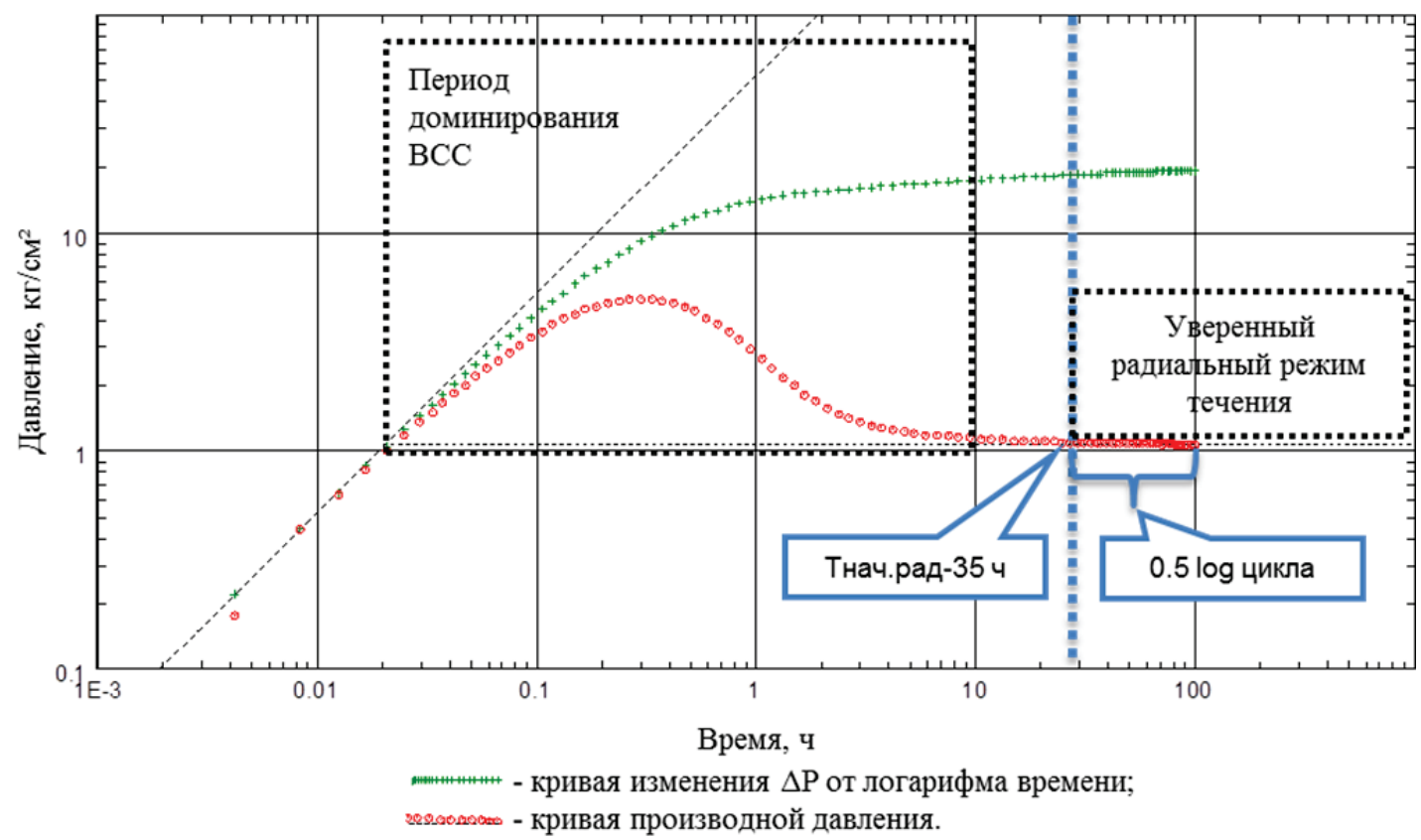

Pис. 4. Дизайн диагностического графика КвД скважины Т-23 в билогарифмических координатах

Fig. 4. Diagnostic chart design of well T-23 PBU in logarithmic coordinates

На полученном диагностическом графике математического моделирования КВД в билогарифмических координатах наблюдается длительный период влияния ствола скважины, осложненный фазовыми перераспределениями - 35 часов, время выхода на радиальное течение составляет порядка 38 часов.

Из рис. 6 видно, фактическое Тнач.рад - начало выхода на радиальный режим течения - диагностируется спустя 38 часов, при этом Тнач.рад, полу- ченное в результате моделирования дизайна исследования, составило 35 часов. Вышеприведенные данные подтверждают высокую эффективность применения методики разработки комплексного подхода к моделированию процесса проведения исследований, основанного на создании дизайна.

\section{Экономический эффект}

В период планирования ГДИ на этапе опытнопромышленной эксплуатации скважин фактором 


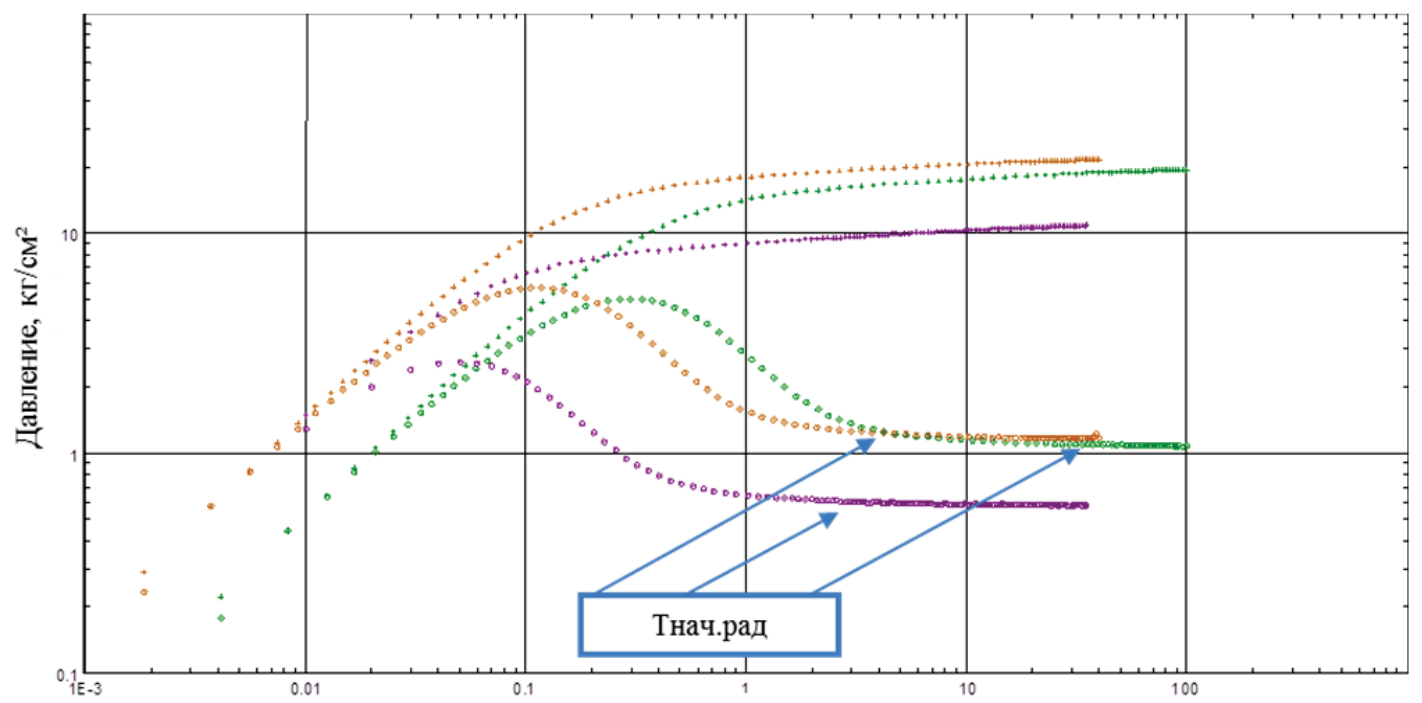

Время, ч

- дизайн скважины Т-23;

- дизайн скважины Т-361;

- дизайн скважины Т-388.

Pис. 5. Дизайн диагностического графика КВД скважин T-23, T-361, T-388 в билогарифмических координатах

Fig. 5. Diagnostic chart design of wells T-23, T-361, T-388 PBU in logarithmic coordinates

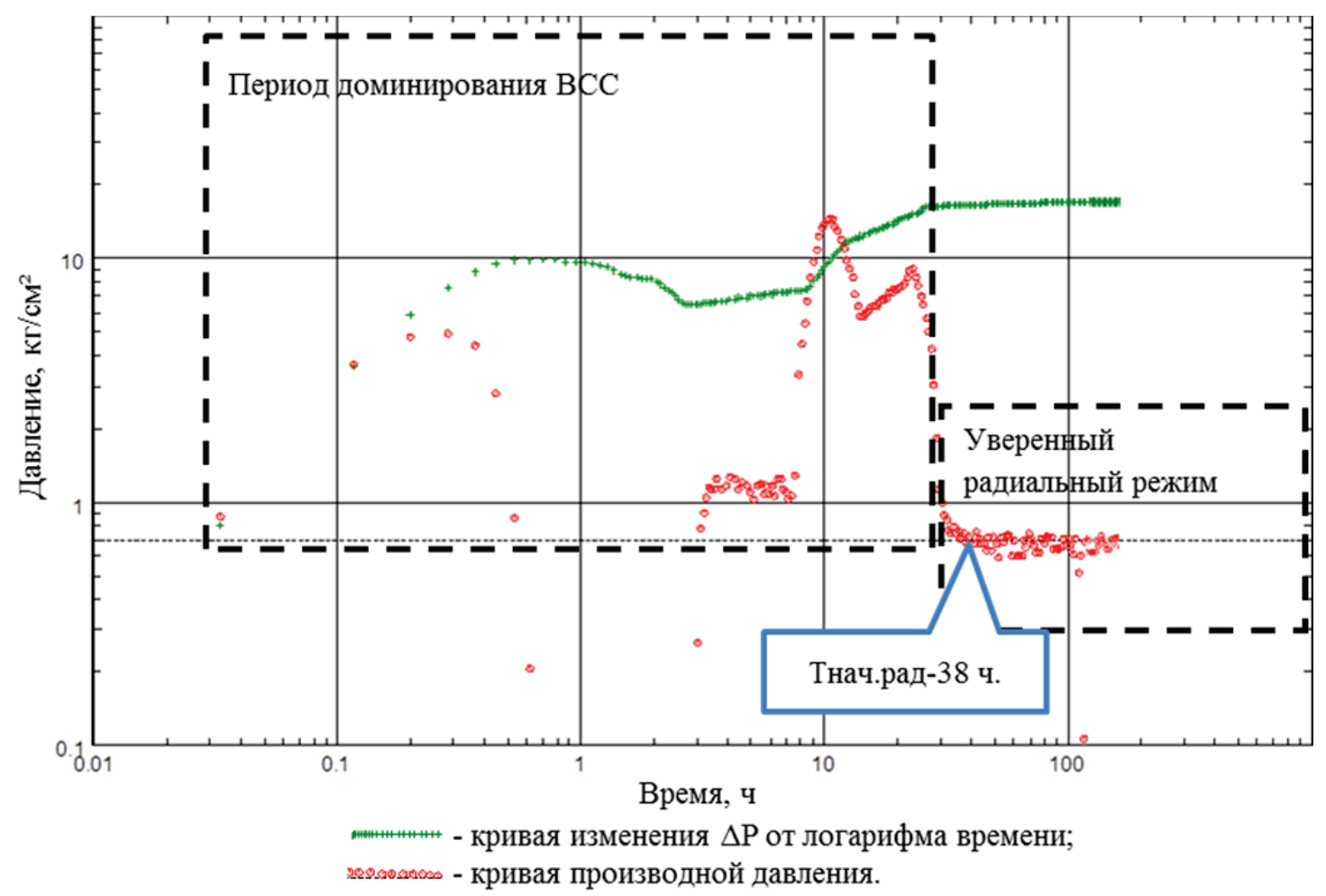

Pис. 6. Фактический диагностический график КВД скважины Т-23 в билогарифмических координатах

Fig. 6. Actual diagnostic chart of well T-23 PBU in logarithmic coordinates

для экономической оценки является время проведения исследований. Чем меньше период проведения ГДИ и, как следствие, период остановки скважины, тем проект выгоднее.
С целью оценки экономической эффективности представленного подхода был проведен сравнительный анализ. При сравнении использовались рекомендации, указанные в РД 153-39.0-109-01, 
в соответствии с геологическими условиями, а также данные, полученные в результате моделирования дизайна исследования. Исходя из рекомендаций, указанных в РД, необходимое время эксплуатации скважины на одном режиме для коллектора с проницаемостью 0,05-0,01 мкм² составляет 96 часов, а время снятия КВД -144 часа [14].

Исходные данные для расчета представлены в табл. 7.

Таблица 7. Исходные данные для экономического анализа

Table 7. Basic data for economic analysis

\begin{tabular}{|c|c|c|c|}
\hline \multicolumn{4}{|c|}{ Технические характеристики/Technical characteristics } \\
\hline Скважина/Well & T-23 & $\mathrm{T}-361$ & T-388 \\
\hline Дебит $Q_{\text {нефти }}$, т/сут./Flow rate, tpd. & 150,3 & 254,0 & 111,8 \\
\hline \multicolumn{4}{|c|}{$\begin{array}{l}\text { Bремя снятия кривой восстановления забойного давления, сут.: } \\
\text { Time of pressure buildup plot fixation, d: }\end{array}$} \\
\hline $\begin{array}{l}\text { Стандартная методика РД 153-39.0-109-01 } T_{1} \\
\text { Standard method Ruling document } \\
\text { 153-39.0-109-01 }\end{array}$ & 6 & 6 & 6 \\
\hline $\begin{array}{l}\text { Методика тест-дизайна } T_{2} \\
\text { Method of test-design }\end{array}$ & 4,2 & 1,7 & 1,5 \\
\hline \multicolumn{4}{|c|}{ Экономические макропараметры/Economic macroparameters } \\
\hline \multicolumn{3}{|c|}{$\begin{array}{l}\text { Цена нефти } S_{\text {барр }} \text { (среднее за год, по данным на февраль } \\
2018 \text { г.), \$/бapp. } \\
\text { Oil price (average for a year, according to the February } \\
2018 \text { data), } \$ \text { /bbl }\end{array}$} & 68,95 \\
\hline \multicolumn{3}{|c|}{$\begin{array}{l}\text { Коэффициент барреляжа } K_{\text {барр }} \text { (по данным Аналитического } \\
\text { агентства АРГУС), барр/т } \\
\text { Bbl coefficient (according to the ARGUS analytic agency data), bbl/t }\end{array}$} & 7,43 \\
\hline
\end{tabular}

Как упоминалось выше, при рассмотрении стандартного подхода минимальное время снятия кривой восстановления забойного давления $T_{1}=144$ часа (6 суток) принято для скважин с высокими устойчивыми дебитами и коллекторов с проницаемостью ниже 0,05-0,01 мкм²

Цена нефти S, \$/тонн $[15,16]$ :

$$
S_{\text {тонн }}=S_{\text {барр }} \cdot K_{\text {барр }}=
$$

$$
=68,95 \text { \$ барp · 7,43 барp / ò =512,30\$ / ò . }
$$

С учетом курса доллара (по данным на февраль 2018 г.) $S_{\$}=57,66$ руб $/ \$$, стоимость нефти $\mathrm{S}$, тыс. p./т:

$$
S=S_{\text {тонн }} \cdot S_{\$}=
$$

$=512,30$ \$ т ·57, 66 руб $/ \$=29,54$ тыс. руб $/$ т.

Масса нефти, полученной в процессе проведения ГДИ, в зависимости от применяемой методики прогнозирования ГДИ, т:

$$
M_{\text {н }}=Q_{\text {нефти }} T .
$$

Экономический эффект при применении методики создания дизайна по сравнению со стандартным подходом рассчитывался по формуле [17-19]:

$$
\ni=\left(M_{\mathrm{H} 1}-M_{\mathrm{H} 2}\right) S .
$$

В табл. 8 представлены результаты экономических расчетов.

Из вышеприведенных данных следует, что экономический эффект от применения представленной методики прогнозирования исследования, основанного на создании дизайна, в сравнении со стандартным подходом по РД 153-39.0-109-01 для рассматриваемых скважин месторождения $\mathrm{N}$, составит:

\begin{tabular}{|c|c|c|c|c|c|c|c|}
\hline \multirow{2}{*}{ 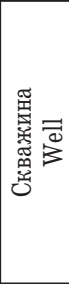 } & \multirow{2}{*}{ 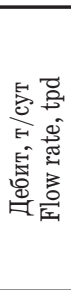 } & \multicolumn{2}{|c|}{$\begin{array}{c}\text { Длитель- } \\
\text { ность, сут } \\
\text { Period, d }\end{array}$} & \multicolumn{2}{|c|}{$\begin{array}{c}\text { Потери } \\
\text { нефти, т } \\
\text { Oil losses, t }\end{array}$} & \multirow{2}{*}{ 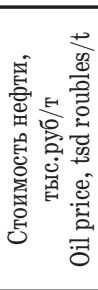 } & \multirow{2}{*}{ 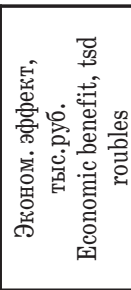 } \\
\hline & & 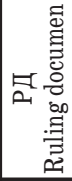 & 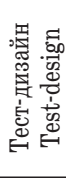 & 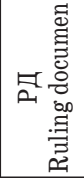 & 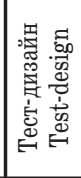 & & \\
\hline № & $\mathrm{Q}_{\text {нефти }}$ & $\mathrm{T}_{1}$ & $\mathrm{~T}_{2}$ & $\mathrm{MH}_{1}$ & $\mathrm{MH}_{2}$ & $\mathrm{~S}$ & $\ni$ \\
\hline T-23 & 150,3 & 6 & 4,2 & 901,8 & 631,3 & \multirow{3}{*}{29,54} & 7991,8 \\
\hline T-361 & 254,0 & 6 & 1,7 & 1524,0 & 431,8 & & 32263,6 \\
\hline T-388 & 111,8 & 6 & 1,5 & 670,8 & \begin{tabular}{|l|}
167,7 \\
\end{tabular} & & 14861,6 \\
\hline
\end{tabular}
$\vartheta_{1}=7991,8$ тыс. руб.; $Э_{2}=32263,6$ тыс. руб.; $\vartheta_{1}=14861,6$ тыс. руб.

Таблица 8. Результаты экономического сравнения методик Table 8. Results of methods economic comparison

Можно заключить, что методика создания дизайна исследования позволяет сократить срок проведения ГДИ на стадии планирования. Таким образом, период остановки скважины уменьшится, что позволит сократить потери на этапе опытнопромышленной эксплуатации скважин и получить дополнительную выгоду от реализации продукта (рис. 7).

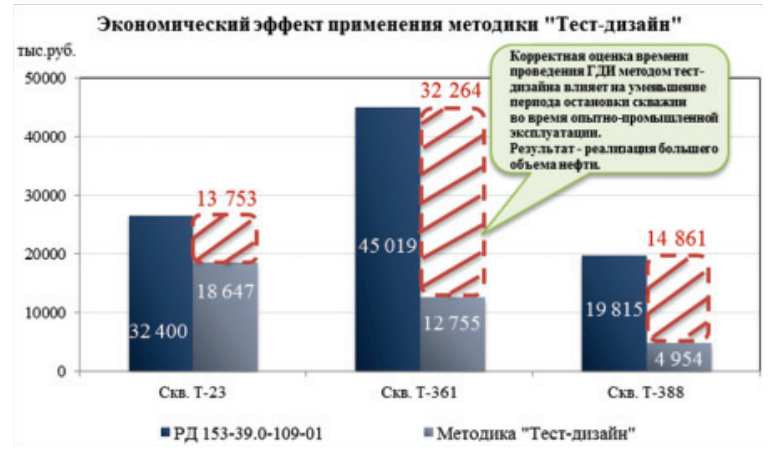

Pис. 7. Результаты экономического сравнения методик

Fig. 7. Results of technical and economic comparison

\section{Выводы}

В результате выполненного дизайна был произведен тщательный анализ исходных данных и численное моделирование поведения забойного давления в скважинах Т-23, Т-361, Т-388. По результатам моделирования исследования рекомендованная продолжительность исследования составила:

- T-23- 100 ч;

- T-361- 40 ч;

- Т-388- 35 ч.

Потери по нефти для исследуемых скважин при остановке будут составлять:

- $\mathrm{T}-23-631,3 \mathrm{~T}$;

- T-361-431,8 т;

- T-388-167,7 т. 
Для скважины Т-23 также был проведен анализ сопоставления с реальными данными исследования. В ходе данного анализа было установлено, что выбранный дизайн исследования и проведенные расчеты полностью подтверждаются.

В статье подтверждена экономическая целесообразность моделирования ГДИ, основанного на создании дизайна исследования. Уточнение времени проведения исследований по сравнению со стандартным подходом РД 153-39.0-109-01 позволяет сократить период остановки скважины и увеличить время добычи нефти на этапе опытно-промышленной эксплуатации. Усреднённое значение экономического эффекта на основе данных по трем разведочным скважинам месторождения А составило 20 292,7 тыс. р.

В условиях сформированной системы разработки месторождений для повышения качества ГДИС требуются: обязательная точная постановка целей гидродинамического исследования в адресной скважине с определением возможностей того или иного метода ГДИС, а также обязательное соблюдение технологии исследования, изложенной в дизайне. Это позволит значительно повысить качество ГДИС, оптимизировать затраты на исследования и потери по нефти, компенсируя их высокой точностью полученной информации. Предложенные в статье решения позволяют оценить целесооб-

\section{СПИСОК ЛИТЕРАТУРЫ}

1. Гидродинамические исследования скважин: анализ и интерпретация данных / Т.А. Деева, М.Р. Камартдинов, Т.Е. Кулагина, П.В. Мангазеев. - Томск: Изд-во ТПУ, 2009. - 243 с.

2. Покрепин Б.В. Разработка нефтяных и газовых месторождений. - Волгоград: Изд-во «Ин-Фолио», 2008. - 192 с.

3. Алтунина Л.К., Кувшинов В.А., Кувшинов И.В. Увеличение нефтеотдачи в карбонатных коллекторах // Деловой журнал NEFTEGAZ.RU. - 2017. - № 3. - C. 99-103.

4. Васильева К.Ю. Стадийность постседиментационных изменений карбонатных пород рифея-венда Куюмбинского месторождения и ее связь с геологической эволюцией Байкитской антеклизы (юго-запад Сибирской платформы). - СПб: СПБУ, 2017. $-138 \mathrm{c}$.

5. Методические рекомендации по изучению и прогнозу коллекторов нефти и газа сложного типа. - Л.: Недра, 1989. - 103 с.

6. Интерпретация и анализ результатов исследований коллектора трещинно-кавернозно-порового типа / В.А. Байков, О.В. Емченко, А.В. Зайнулин, А.Я. Давлетбаев // Научнотех нический вестник 0АО «НК «Роснефть». - 2007. - № 5. C. $30-34$.

7. Белоновская Л.Г. Трещиноватость карбоновых пород и разработанные во ВНИГРИ основы поисков трещинных коллекторов нефти и газа // Нефтегазовая геология. Теория и практика. - 2006. - T. 1. URL: http://www.ngtp.ru/rub/10/04.pdf

8. Houze 0., Viturat D., Fjaere O.S. Dynamic Data Analysis v4.12.02 // The Kappa Journal. - 2011. - V. 10 - № 3. P. 530-557.

9. Манометры-термометры глубинные «САMT-02-25-d32», «CAMT-02-40-d32», «CAMT-02-60-d32». Руководство по эксплуатации. - М.: Сиам, 2010. - 13 с

10. Earlaugher R.C. Jr., Kerch K.M. Analysis of short-time transient test data by type-curve matching // Journal of petroleum technologies. - 1974. - V. 26. - P. 793-800. разность и экономическую эффективность планируемых работ.

Очевидно, что для проведения качественных исследований необходимо планировать ГДИС на этапе, предшествующем замерам. Иными словами, перед выполнением любого ГДИС следует выполнить его дизайн либо в специализированном программном продукте, либо по эмпирическим формулам [20-23].

Важно отметить, что как бы идеально не было спланировано исследование, необходимо обеспечить технические (подготовка скважины, выбор работоспособного исследовательского оборудования) и технологические (соблюдение длительности исследования) условия проведения работ в адресной скважине каждой из ответственных сторон (нефтяной компанией и сервисным предприятием). Кроме того, необходимо установить, что именно может помешать получению отчетливо диагностируемого участка радиального течения. С одной стороны, радиальное течение может «маскироваться» влиянием әффекта ствола скважины либо линейным течением в случае скважины с трещиной. С другой стороны, радиальный режим притока может быть искажен проявлением следующих граничных условий: 1) интерференции с окружающими скважинами; 2) геологического разлома (наличие непроницаемой границы); 3) газовой шапки (границы постоянного давления).

11. Gringarten A.C. Well Test Analysis in Practice // The way ahead (TWA) Journal. - 2012. - V. 36. - № 8. - P. 10-15.

12. Horne R.N. Modern Well Test Analysis. A computer Aided Approach // The Petroway Journal of Science. - 1990. - V. 12. № 3. - P. 180-185.

13. Gao B. Pressure Transient Analysis of a Well Penetrating a Filled Cavity in Naturally Fractured Carbonate Reservoirs / / Journal of Petroleum Science and Engineering - 2016. - V. 24. P. 392-403.

14. Руководящий документ РД 153-39.0-109-01. Методические указания по комплексированию и этапности выполнения геофизических, гидродинамических и геохимических исследований нефтяных и нефтегазовых месторождений (утв. Приказом Минэнерго России от 5 февраля 2002 г. N 30). - М.: Наука, 2002. $-95 \mathrm{c}$.

15. Патрушева Е.Г. Инвестиционный менеджмент. - Ярославль: ЯрГУ, 2017. - 120 c.

16. Кочетков А.А. Экономическая теория. - М.: Дашков и $\mathrm{K}$, 2016. $-696 \mathrm{c}$

17. Давыдова А.Е., Гроо А.А. Разработка расчетного комплекса поверхностного обустройства 0-d уровня // Сборник докладов VIII Региональной научно-технической конференции молодых специалистов 000 «РН-КрасноярскНИПИнефть». - Красноярск, 2016. - С. 73-78.

18. Расчет экономической эффективности новых технологических процессов / И.М. Бабук, А.А. Королько, С.И. Адаменкова, Е.Н. Костюкевич. - Минск: БНТУ, 2010. - 56 с.

19. Impact of Oil Prices on Nominal Exchange Rate: Evidence from Ghana / G. Acka, A. Mohammed, J. Ampomah, D. Oppong, 0 . Sampah // The International Journal of Business \& Management. - 2017. - V. 73. - P. 269-281.

20. Bourde D. Well Test Analysis: the Use of Advanced Interpretation Models. - Amsterdam, Netherlands: Elsevier science, 2002. $-461 \mathrm{p}$. 
21. Economides M., Daniel H. Petroleum production systems. - Upper Saddle River: Prentice Hall Inc, 1994. - 607 p.

22. Adedapo A., Ayham A. A Cohesive Approach at Estimating Water Saturation in a Low-Resistivity Pay Carbonate Reservoir and Its Validation // Journal of Petroleum Exploration and Production Technology. - 2017. - V. 67. - P. 306-320.
23. Arbab B., Jahani D., Movahed B. Reservoir Characterization of Carbonate in Low Resistivity Pays Zones in the Buwaib Formation, Persian Gulf // Open Journal of Geology. - 2017. - V. 22. P. 1441-1451.

Поступила 16.11.2018 г.

\section{Информация об авторах}

Давыдова A.E., аспирант кафедры разработки и эксплуатации нефтяных и газовых месторождений Института нефти и газа Сибирского Федерального университета; главный специалист департамента проектирования разработки $О О 0$ «РН-КрасноярскНИПИнефть».

Щуренко A.A., аспирант кафедры разработки и эксплуатации нефтяных и газовых месторождений Института нефти и газа Сибирского Федерального университета; главный специалист департамента проектирования разработки $О 00$ «РН-КрасноярскНИПИнефть».

Дадакин Н.М., аспирант кафедры разработки и эксплуатации нефтяных и газовых месторождений Института нефти и газа Сибирского Федерального университета; главный инженер проекта департамента проектирования разработки 000 «РН-КрасноярскНИПИнефть».

Шуталев А.Д., аспирант кафедры разработки и эксплуатации нефтяных и газовых месторождений Института нефти и газа Сибирского Федерального университета; главный специалист департамента проектирования разработки 000 «РН-КрасноярскНИПИнефть».

Квеско Б. Б., кандидат физико-математических наук, профессор кафедры разработки и эксплуатации нефтяных и газовых месторождений Института нефти и газа Сибирского Федерального университета. 
UDC 622.276

\title{
WELL TESTING DESIGN DEVELOPMENT IN CARBONATE RESERVOIR
}

\author{
Anastasiya E. Davydova ${ }^{1,2}$, \\ DavydovaAE@knipi.rosneft.ru
}

\author{
Alexander A. Shchurenko, , \\ ShchurenkoAA@knipi.rosneft.ru \\ Nikita M. Dadakin ${ }^{1,2}$ \\ DadakinNM@knipi.rosneft.ru

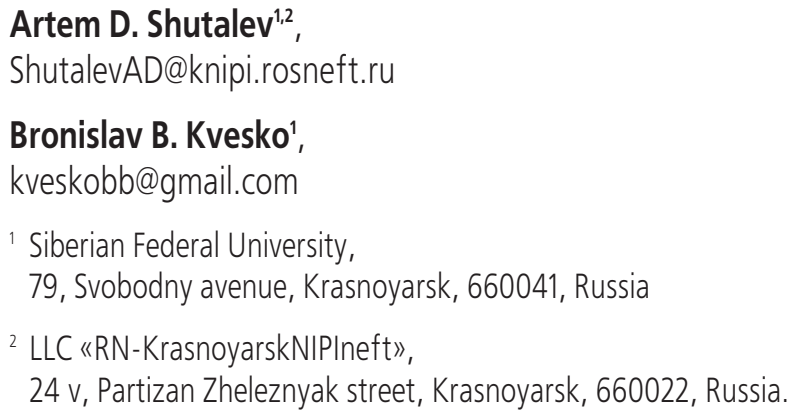

The relevance of the research is caused by the need to improve the methods of well testing due to the ambiguous interpretation of the results in a carbonate reservoir. Priorities in well testing are the maximum quality of the information obtained on the reservoir filtration and reservoir properties and the minimum loss of oil production during the shutdown of wells for research. In order to perform these tasks, it is important to develop the design of the well testing proposed in the article. The design will provide an integrated approach to modeling the process of conducting research and forecasting the data received.

The main aim of the research is to develop the design of well testing in order to optimize the time of the research and reduce the period of shutdown of wells at the stage of pilot operation, as well as to confirm the economic effectiveness of the presented methodology.

Objects: wells T-23, T-361, T-388 of oilfield A, the productive deposits of which are mainly represented by strong cavernous-fissured carbonate rocks of Riphean age.

Methods. The set research tasks were solved theoretically and experimentally under field conditions. At the same time, the analysis of publications on this issue was carried out; field hydrodynamic studies of wells that open a low permeable carbonate reservoir were conducted; simulation of hydrodynamic studies was carried out, comparative calculations were carried out for processing the results using the Saphir software package of KAPPA Engineering.

Results. This article presents the results of developing the design of hydrodynamic studies in a carbonate reservoir. The data of hydrodynamic studies for 12 wells operating Riphean carbonate sediments were analyzed for 2005-2008, the results for three wells: T-23, T$361, T-388$, are presented. The technique of simulation of hydrodynamic researches in the software complex Saphir of the company "KAPPA Engineering» is presented. The paper introduces the example of calculation of the stabilization time in the study of the well by the method of steady-state sampling, as well as estimation of the optimum time for recording the pressure recovery curve. Also, the article compares the standard methodology used for testing a well - RD (ruling document) 153-39.0-109-01 «Methodological guidelines for the integration and phasing of geophysical, hydrodynamic and geochemical studies of oil and oil and gas fields» with that presented in the article. Based on this comparison, the economic efficiency was established.

\section{Key words:}

Well testing, build-up test, design, duration of well investigation, carbonate reservoir, oil and gas field.

\section{REFERENCES}

1. Deeva T.A., Kamartdinov M.R., Kulagina T.E., Mangazeev P.V. Gidrodinamicheskie issledovaniya skvazhin: analis i interpretatsiya dannykh [Well test: analysis and interpretation of data]. Tomsk, Tomsk Polytechnic University Publ., 2009. 243 p.

2. Pokrepin B.V. Razrabotka neftyanykh i gasovykh mestorozhdeniy [Development of oil and gas fields]. Volgograd, In-Folio Publ., 2008. $192 \mathrm{p}$

3. Altunina L.K., Kuvshinov V.A., Kuvshinov I.V. Uvelichenie nefteotdachi v karbonatnykh kollectorakh [0il recovery increase in carbonate reservoirs]. Bizness zhurnal neftegaz.ru, 2017, vol. 47 , no. 3, pp. 99-103.

4. Vasilieva K.Yu. Stadiynost postsedimentatsionnykh izmeneniy karbonatnykh porod rifeya - venda Kuymbinskogo mestorozhdeniya i ee suyaz s geologicheskoy evolutsiey Baikitskoy anteklizy (yu- go-zapad Sibirskoy platformy) [Stages of post-sedimentation changes in the carbonate rocks of the Riphean-Vendian of the Kuyumba deposit and its relationship to the geological evolution of the Baikit anteclise (southwest of the Siberian platform)]. Saint-Petersburg, Saint-Petersburg State University Publ., 2017. 138 p.

5. Metodicheslie recomendatsii po izucheniyu i prognozu kollektorov nefti i gaza slozhnogo tipa [Methodological recommendations for the study and forecast of oil and gas collectors of complex type]. Saint-Petersburg, Nedra Publ., 1989. 103 p.

6. Baikov V.A., Emchenko 0.V., Zaynulin A.V., Davletbaev A.Ya. Interpretatsiya $\mathrm{i}$ analiz rezultatov issledovaniy kollektora trezhinno-kavernozno-porovogo tipa [Interpretation and analysis of the results of investigations of the reservoir of a crack-cavernous-pore type]. Nauchno-tehnicheskii vestnik, 2007, vol. 10, pp. $30-34$. 
7. Belonovskaya L.G. Treshchinovatost karbonatnykh porod i razrabotannye vo VNIGRI osnovy poiskov treshchinnykh kollektorov nefti i gaza [Fracture of carbon rocks and the foundations of the search for fractured reservoirs of oil and gas developed in VNIGRI]. Neftegazovaya geologiya. Teoriya i praktika, 2006, no. 8, pp. $9-13$.

8. Houze 0., Viturat D., Fjaere O.S. Dynamic Data Analysis v4.12.02. The Kappa Journal, 2011, vol. 10, no. 3, pp. 530-557.

9. Manometry-termometry glubinnye «SAMT-02-25-d32», «SAMT 02-40-d32», «SAMT-02-60-d32» [Manometers-thermometers «SAMT-02-25-d32», «SAMT-02-40-d32», «SAMT-02-60-d32»]. Moscow, Siam Publ., 2010. 13 p.

10. Earlaugher R.C. Jr., Kerch K.M. Analysis of short-time transient test data by type-curve matching. Journal of petroleum technologies, 1974, vol. 26, pp. 793-800.

11. Gringarten A.C. Well Test Analysis in Practice. The way ahead (TWA) Journal, 2012, vol. 36, no. 8, pp. 10-15.

12. Horne R.N. Modern Well Test Analysis. A computer Aided Approach. The Petroway Journal of Science, 1990, vol. 12, no. 3, pp. $180-185$.

13. Gao B. Pressure Transient Analysis of a Well Penetrating a Filled Cavity in Naturally Fractured Carbonate Reservoirs. Journal of Petroleum Science and Engineering, 2016, vol. 24, pp. 392-403.

14. Rukovodyashchiy dokument RD 153-39.0-109-01. Metodicheskie ukazaniya po kompleksirovaniyu i etapnosti vypolneniya geofizicheskikh, gidrodinamicheskikh $i$ geokhimicheskikh issledovaniy neftyanykh i neftegazovykh mestorogdeniy [Ruling document RD 153-39.0-109-01. Methodical instructions on complexation and phasing of geophysical, hydrodynamic and geochemical studies of oil and oil and gas fields]. Moscow, Nauka Publ., 2002. 95 p.
15. Patrusheva E.G. Investitsionniy menedzhment [Investment management]. Yaroslavl, Yaroslavl State University Publ., 2017. $120 \mathrm{p}$.

16. Kochetkov A.A. Ekonomicheskaya teoriya [Economic Theory]. Moscow, Dashkov and K Publ., 2016. 696 p.

17. Davydova A.E., Groo A.A. Razrabotka rashchetnogo kompleksa poverkhnostnogo obustroistva 0-d urounya [Calculation complex development of 0-d level infrastructure development]. Krasnoyarsk, KrasnoyarskNIPIneft Publ., 2016. 108 p.

18. Babuk I.M., Korolko A.A., Adamenkova S.I., Kostyukevich E.N. Raschet ekonomicheskoy effectivnosti novykh tekhnologicheskikh protsessou [Calculation of economic efficiency of new technological processes]. Minsk, BNTU Publ., 2010. 56 p.

19. Acka G., Mohammed A., Ampomah J., Oppong D., Sampah 0. Impact of Oil Prices on Nominal Exchange Rate: Evidence from Ghana. The International Journal of Business \& Management, 2017, vol. 73, pp. 269-281.

20. Bourde D. Well Test Analysis: the Use of Advanced Interpretation Models. Amsterdam, Netherlands, Elsevier science, 2002. $461 \mathrm{p}$.

21. Economides M., Daniel H. Petroleum production systems. Upper Saddle River, Prentice Hall Inc, 1994. 607 p.

22. Adedapo A., Ayham A. A Cohesive Approach at Estimating Water Saturation in a Low-Resistivity Pay Carbonate Reservoir and Its Validation. Journal of Petroleum Exploration and Production Technology, 2017, vol. 67, pp. 306-320.

23. Arbab B., Jahani D., Movahed B. Reservoir Characterization of Carbonate in Low Resistivity Pays Zones in the Buwaib Formation, Persian Gulf. Open Journal of Geology, 2017, vol. 22, pp. 1441-1451.

Received: 16 November 2018.

\section{Information about the authors}

Anastasiya E. Davydova, graduate student, Siberian Federal University; chief specialist, LLC «RN-KrasnoyarskNIPIneft».

Alexander A. Shchurenko, graduate student, Siberian Federal University; chief specialist, LLC «RN-KrasnoyarskNIPIneft».

Nikita M. Dadakin, graduate student, Siberian Federal University; chief project engineer, LLC «RN-KrasnoyarskNIPIneft».

Artem D. Shutalev, graduate student, Siberian Federal University; chief project engineer, LLC «RN-KrasnoyarskNIPIneft».

Bronislav B. Kvesko, Cand. Sc., professor, Siberian Federal University. 